\title{
A comparative analysis of changes in anti-immigrant and anti-Muslim attitudes in Europe: 1990-2017
}

\author{
David Andreas Bell ${ }^{1 *}$, Marko Valenta ${ }^{1}$ and Zan Strabac ${ }^{2}$
}

\author{
*Correspondence: \\ david.a.bell@ntnu.no \\ ${ }^{1}$ Department of Social \\ Work, Norwegian University \\ of Science and Technology, \\ 7491 Trondheim, Trondelag, \\ Norway \\ Full list of author information \\ is available at the end of the \\ article
}

\begin{abstract}
Muslims and immigrants have both been subjected to negative attitudes over the past several decades in Europe. Using data from the European Values Study, this study analyses the changes in these attitudes in the period 1990-2017. We find that negative attitudes have been increasing on average in Europe as a whole, with anti-Muslim attitudes being more prevalent than anti-immigrant attitudes. However, when split into a Western European set and an Eastern European set, from 2008, there is a divergence between the two halves. Our findings reveal that negative attitudes towards Muslims and immigrants have decreased in Western Europe, whereas they have increased significantly in Eastern Europe. Further analyses find that there are large discrepancies between anti-Muslim and anti-immigrant attitudes in different countries. These discrepancies are discussed in detail and related to several relevant factors, such as the differences in size of the Muslim and immigrant populations, variations in the refugee influx and other possible factors and developments.
\end{abstract}

Keywords: Anti-Muslim, Anti-Immigrant, Islamophobia, Prejudice, Western Europe, Eastern Europe, European Values Study, Attitudes

\section{Introduction}

Exclusionary attitudes towards both immigrants and Muslims can be found in virtually every European country (Gorodzeisky \& Semyonov, 2019). Muslim immigrants, in particular, face a twofold challenge: in addition to being the target of the prejudice and discrimination that exists towards all non-Western immigrants, Muslim immigrants are also subjected to specific prejudices, stereotypes and discrimination because of their religion. Examples of this can include negative attitudes towards Muslim women wearing headscarves or that people connect Muslims to crime or terrorism (Andersen \& Mayerl, 2018; Strabac et al., 2016; Gorodzeisky \& Semyonov, 2019).

Both Western and Eastern Europe have experienced a rise in right-wing populist parties over the last decade. Central to many of these parties is an emphasis on a supposed threat from Muslims and Islam (Brubaker, 2017). Despite prejudice towards minorities becoming more prevalent in Western Europe since the late 1980s (Semyonov et al., 2006), studies continually report higher levels of both anti-Muslim and anti-immigrant author(s) and the source, provide a link to the Creative Commons licence, and indicate if changes were made. The images or other third party material in this article are included in the article's Creative Commons licence, unless indicated otherwise in a credit line to the material. If material is not included in the article's Creative Commons licence and your intended use is not permitted by statutory regulation or exceeds the permitted use, you will need to obtain permission directly from the copyright holder. To view a copy of this licence, visit http:// creativecommons.org/licenses/by/4.0/. 
attitudes in Eastern European countries (Strabac \& Listhaug, 2008; Bello, 2017; Gorodzeisky \& Semyonov, 2019). This is somewhat a strange paradox, as there are significantly fewer immigrants and Muslims in Eastern European countries. The term "phantom islamophobia" was used to describe the situation in Poland, where there are high levels of anti-Muslim attitudes, despite there being a nearly non-existent population of Muslims (Włoch, 2009). As we will soon see, this term could easily be applied to several other Eastern European countries, including Lithuania, Czech Republic and Slovakia, where, despite Muslims making up a very low percentage of the population, there remains a high level of anti-Muslim attitudes.

Regarding the anti-Muslim and anti-immigrant attitudes in Eastern Europe, there is relatively little understanding of how these attitudes have evolved over time. This is mainly due to a lack of reliable cross-country data from different time periods in Eastern Europe. Although some studies have explored anti-immigrant attitudes over time in Western Europe (Czaika \& Di Lillo, 2018; Meuleman et al., 2009; Semyonov et al., 2006), ${ }^{1}$ the lack of data from Eastern Europe means there is an incomplete picture of the changes in attitudes in Europe. Using data collected by the European Values Study (EVS) from more than 30 European countries during the period 1990 to 2017, this study we explores changes over time in anti-immigrant and anti-Muslim attitudes in Europe. Our focus is twofold, exploring variations in attitudes that exist both in space and time. The first is to explore and compare the differences in anti-Muslim and anti-immigrant attitudes in both Western and Eastern Europe, and the second is to scrutinise and compare developments over time in attitudes across the above-mentioned time period.

At this point, we may note that there are several other dimensions we could scrutinise instead of the above-mentioned differences between Western and Eastern Europe, such as North-South division, which could include a larger focus on Mediterranean region which have had unique historical contact with the Muslim Mediterranean world. ${ }^{2}$ However, we have chosen to focus primarily on the East-West division as the divergence in attitudes between Western and Eastern Europe is the most prominent.

In addition to exploring the above-mentioned space-time dimensions, we will also explore and discuss the potential and limitations of EVS for explaining attitudes over time. We believe that EVS has relatively high potential for a macro-level analysis of attitudes across time. However, when analysing changes across time on a micro level, panel data is the most optimal analytical strategy. Unfortunately, the EVS collects data from different individuals in each survey round, rendering the data unfit for panel-data analysis and for analysing individual-level effects on attitudes across time. However, it is suitable for a potentially promising approach using the construction of what Deaton (1985) introduced as a pseudo-panel analysis. ${ }^{3}$ We therefore construct a pseudo-panel dataset from the EVS data to investigate whether some of these shortcomings may be addressed and compensated for via the construction of a pseudo-panel.

\footnotetext{
${ }^{1}$ Some studies have included Eastern European countries. However, they often make up too small of a sample to yield any substantial claims.

${ }^{2}$ In addition to the historical connections, the countries in the region are also in a unique geographical position as they are the first countries of arrival for refugees and migrants from the Middle East and North Africa. As we will soon see, many of these countries also have relatively high levels of anti-Muslim sentiments. However, anti-Muslim attitudes in Southern Europe are significantly lower than those we may find in Eastern Europe.

${ }^{3}$ For studies using the pseudo-panel approach, see for example Liu and Tan (2009) and Jæger (2013).
} 


\section{Previous research on prejudice towards outgroups}

Negative attitudes towards immigrants are largely understood to be a consequence of a perceived notion of threat. In his group position theory, Blumer (1958) highlighted that in a stratified system, the dominant ethnic/racial group has a feeling of superiority and proprietary claim to certain rights and privileges. The subordinate groups are viewed by the dominant group as being intrinsically alien. Furthermore, the dominant group fears that the subordinate group will threaten their position. It is further suggested that the above-mentioned threat perceptions can be split into either symbolic or realistic threat (Stephan et al., 2015). Symbolic threat is often associated with the in-group's religion, beliefs, values or ideologies, ${ }^{4}$ while realistic threat is linked to economic and security concerns. Different dimensions of threat perceptions have been found to be connected to different immigrant groups (Ben-Nun Bloom et al., 2015; Gorodzeisky, 2019).

For example, Ben-Nun Bloom and colleagues' (2015) study found that culturally threatened individuals tend to prefer allowing immigrants who are ethnically more like themselves, whereas economically threatened individuals tend to prefer immigrants from different racial, ethnic or geographical backgrounds, whom they perceive as being less likely to compete with them for economic resources. Furthermore, Blalock (1967) postulated that when the relative size of a minority outgroup increases, there would be increased fear of competition between groups, which in turn would lead to intolerant attitudes. However, the notion that an increase in the size of the outgroup leads to an increase in intolerant attitudes has empirically received mixed results in Europe (see Pottie-Sherman \& Wilkes, 2017 for meta-analysis). Misperceptions of the size of a minority on the contrary have been found to have a strong influence on shaping antiimmigrant attitudes. The size of the minority is often grossly overestimated, and these misperceptions are found to play a more important role in increased intolerance than the factual reality (Citrin \& Sides, 2008; Gorodzeisky \& Semyonov, 2020).

A competing theoretical perspective about the effect of a minority size comes from intergroup contact theory (Allport, 1954). Positive contact with a minority outgroup has generally been found to have a positive effect on attitudes towards outgroups (Pettigrew \& Tropp, 2006; Verkuyten et al., 2010). A larger minority size might therefore actually improve anti-minority attitudes, because an increase in the size of the minority is associated with an increased chance for personal and positive intergroup contact with the minority (Schlueter \& Wagner, 2008).

A central aspect of our study is analysing both anti-immigrant and anti-Muslim attitudes across time. To our knowledge, due to a lack of data, there are few international comparative studies that have analysed changes in anti-Muslim attitudes over time. There are, by contrast, several international comparative studies that analyse changes in attitudes towards different immigrant groups (Meuleman et al., 2009; Pichler, 2010; Semyonov et al., 2006).

Semyonov et al (2006) show that in the period 1988 to 2000, there was a significant rise in anti-foreigner attitudes in 12 Western European countries, highlighting a steep increase from 1988 to 1994 and a levelling off from 1994 to 2000 (Semyonov et al., 2006). However, Meuleman and colleagues (2009) found mixed results in 17 European

${ }^{4}$ It is worth mentioning that Blumer (1958) would suggest that the feeling of superiority may be rooted in ethnic/racia differences and antagonism and not necessarily dependent on differences in real values or beliefs. 
countries between 2002 and 2007. ${ }^{5}$ Pichler (2010) observed similar results in an exploration of different threat perceptions in 24 European countries from 2002 to 2006, finding that the overall perceived threat had remained stable, while economic threat perceptions had a curvilinear effect, increasing between 2002 and 2004, but then decreasing to the levels of 2002 in 2006. The cultural threat perception, on the other hand, steadily increased from 2002 to 2006. More recently, Czaika and Di Lillo (2018) found that negative attitudes towards most immigrants have decreased, except for towards immigrants from poorer countries outside of the EU. Dennison and Geddes (2019) showed that antiimmigrant attitudes decreased in 12 Western European countries in the period between 2014 and 2017, despite an increase in support for anti-immigrant parties.

To summarise, an overview of the relevant studies on changes over time in anti-immigrant attitudes shows mixed results in a broad sense. On the one hand, some studies show a stagnation or a modest decrease in negative attitudes, whereas on the other hand, there have been signs of increased intolerance towards immigrants from poor countries outside of the EU and culturally dissimilar immigrants. It should, however, be noted that most of these studies have samples that tend to overrepresent Western European countries. The lack of representation of Eastern European countries may result in an incomplete picture being offered of the attitudinal trends in the whole of Europe. In this article, we provide a more balanced sample. We contribute to the field by including the Eastern European dimension in discussions of changes in anti-immigrant attitudes in Europe over time and show the importance of splitting European datasets into a Western and Eastern European sample when analysing trends across time.

\section{Anti-Muslim attitudes}

The phenomenon of anti-Muslim attitudes has deep historical and cultural roots in Europe. However, the terrorist attacks of $9 / 11$ and the subsequent terrorist attacks in Europe can, in many ways, be seen as a watershed moment in terms of the rise of antiMuslim attitudes in the twenty-first century (Esposito \& Kalin, 2011). ${ }^{6}$ Saeed (2007) showed that from 2001 to 2002, following the terrorist attacks of 9/11, there was a dramatic increase in articles containing the word "Muslim" in British newspapers. It has further been suggested that Muslims are especially prone to negative media representations, as they are frequently viewed as alien and "other" in the media (Saeed, 2007).

Media representations have long been hypothesised to shape public opinion, as mass media represents an important source of information (Blumer, 1958). This would especially be the case in many Eastern European countries, where Muslim populations are nearly non-existent and where face-to-face interactions between the majority population and Muslims are very rare. In such contexts, the only source of information people would have about Muslims would be the mass media or politicians' hostile rhetoric towards Muslims (Czymara, 2020).

While there are several studies showing how Muslims are negatively portrayed in the media (De Cock et al., 2018; Saeed, 2007), there is limited empirical support for the hypothesis that

\footnotetext{
${ }^{5}$ Three countries witnessed an increase in exclusionary attitudes, whereas seven countries experienced a decrease in negative attitudes. The remaining seven countries saw no significant changes in attitudes in the time period (Meuleman et al., 2009).

${ }^{6}$ Preceding the terrorist attacks of 9/11, the Iranian revolution, a significant influx of Muslim immigrants, and hijacking, hostage-taking and terrorist attacks in the 1980s and 1990s all led to an increased scepticism towards Muslims and Islam leading up to 2001 (Esposito \& Khalin 2011).
} 
media shapes anti-Muslim attitudes as it is difficult to measure quantitatively due to the lack of quality data on the subject. There are some studies trying to empirically discover this link, but their results are inconclusive (Das et al., 2009; Schlueter et al., 2020).

Several studies suggest that there are higher levels of anti-Muslim attitudes than generalised anti-immigrant attitudes across Europe (Strabac \& Listhaug, 2008; Bello, 2017; Gorodzeisky \& Semyonov, 2019). However, while these studies reveal differences between Western and Eastern Europe, they reveal only static differences at a point in time, and not differences in trends which we highlight in this study. For example, in an earlier cross-country study of 30 European countries, Strabac and Listhaug found relatively similar effects of independent variables on anti-Muslim and anti-immigrant attitudes (Strabac \& Listhaug, 2008). They concluded that the underlying mechanisms of anti-Muslim attitudes resemble the mechanisms underlying anti-immigrant attitudes, suggesting that Muslims constitute a new target group for prejudice which had come into the spotlight at the time of the study. This follows what Savelkoul and colleagues (2011) found in that general theories explaining prejudice, such as threat perceptions and intergroup contact theory, can be applied to studying anti-Muslim attitudes.

Several other studies suggest that prejudice towards Muslims can be distinguished from the general form of anti-immigrant attitudes. A study amongst university students in Belgium found that anti-Muslim attitudes could be distinguished from blatant racism, cultural prejudice, economic prejudice and negative attitudes towards asylum seekers (Elchardus \& Spruyt, 2014). What differentiates Muslims from many other outgroups is that they are a religious group as well as often being an immigrant group. Finding that Britons are more opposed to fundamental religious immigrants, be they either Christian or Muslim, Helbling and Traunmüller (2018) conclude that Muslims are not in general viewed more negatively than Christian immigrants. But that individuals are more sceptical to fundamentally religious individuals as it may collide with liberal and secular values. This is further evidenced by studies finding a pronounced difference between Muslim women in general and Muslim women wearing a headscarf (Hellbling, 2014; Strabac, 2016).

Comparative studies that explore developments in the attitudes in different parts of Europe are also of relevance for this article (Brubaker, 2017; Simonsen \& Bonikowski 2020). Rogers Brubaker (2017) points toward the repositioning of populist parties in the last 15 years where Western and Northern European populist parties have shifted from nationalism to "civilizationalism" by combining discourses of Christian culture, secularism and liberalism. While East-Central European countries present themselves as more nationalist, criticising the liberalism of the west and defending the Christian values against the threat of Islam. This follows a recent study finding that civic nationalism has taken an exclusionary turn towards Muslims in North-western Europe in that Muslims are perceived as the antithesis to universalist and liberal ideas (Simonsen \& Bonikowski 2020). Other studies have also shown that individuals have a perception of threat from Muslims and link them to both crime and terrorism (Wike \& Grim, 2010, Andersen \& Mayerl, 2018). More recently, less restrictive integration policies, stronger state support for religious practices and a larger relative size of Muslim minority groups have all been associated with lower levels of anti-Muslim attitudes (Schlueter et al., 2020). 


\section{Data and methods}

This study uses data from the European Values Study (EVS), a large-scale, cross-national and longitudinal survey research program based on basic human values. The EVS has collected data every nine years for the period of 1981 to 2017. Due to various data limitations (to be identified in this section), we have chosen to analyse the periods 1990 to 2017 and 1999 to 2017. The main part of the analysis focuses on macro-level changes in attitudes towards both immigrants and Muslims. Additionally, we explore how EVS and pseudopanel data may be used to analyse attitudes towards immigrants and Muslims over time.

\section{Dependent variables}

Our dependent variables for this analysis are based on a "social distance" question that explores which outgroups respondents find undesirable as neighbours. The question is worded as follows: "On this list are various groups of people. Could you identify any that you would not like to have as neighbours?" The number of groups from which the respondent could choose is different depending on the survey year. Since the 1990 survey, the list has included the five groups: "People of a different race", "Jews", "Gypsy", "Muslims" and "immigrant/foreign worker". The responses to the question were then coded into sets of dummy variables with a value of 1 if the group was mentioned and a value of 0 if the group was not mentioned. For our purposes, we used a dummy variable if the respondent mentioned Muslims for our dependent variable measuring an anti-Muslim attitude. If the respondent mentioned immigrants/foreigners, we used this dummy to measure an anti-immigrant attitude for our other dependent variable. The operationalisation of the variable has a strength in that it is a fairly simple and straightforward question, meaning that it can be assumed that all respondents understand the question. Another strength is that it allows us to explore the differences between anti-immigrant and anti-Muslim attitudes, as they are both part of the same question. The weakness of the variable is that it is dichotomous and therefore cannot express the strength of the negative attitude; it can only show how widespread the attitude is in each particular country. ${ }^{7}$ However, the variable has been used in several other studies (see for example Strabac \& Listhaug, 2008 or Ribberink et al., 2017). Additionally, to test the robustness of the macro-analysis we used data from the European Social Survey which includes a likert-scale variable to measure anti-immigrant attitudes and received similar results as presented later in this study.

\section{Data and methods macro analysis}

As our dependent variable for measuring anti-Muslim attitude was first introduced to the questionnaire in the 1990 survey, for the macro analysis, we use data collected at four time points: 1990, 1999, 2008 and $2017 .{ }^{8}$ The combined datasets for these four surveys include approximately 202,000 individuals across 47 countries. We have removed Armenia, Azerbaijan and Georgia from the dataset, as our focus is on Europe. Due to the

\footnotetext{
${ }^{7}$ An important note for the dependent variable in the pseudo-panel analysis is that because we collapse the data, the dependent variable has several values between 0 and 1 , meaning that we will conduct linear probability models instead of logistic regression models.

8 A possible limitation is that attitudes can fluctuate wildly in response to events happening at the times of sampling (see for example Legewie 2013) which can pose a challenge to the validity of analysis as it uses relatively few time points across a rather long time period. However, because of the number of countries added to the analysis, this should be less of an issue.
} 
study's focus on changes in attitudes over time, we also cut countries that only appear in one of the four surveys. This includes Bosnia, Cyprus, Northern Cyprus, Moldova, Montenegro and Kosovo. In addition, Muslims (around 11,000 individuals) and respondents born outside of the country (around 9800 individuals) were removed. A consequence of this was a drastic decrease in the sample sizes of Albania and Turkey, so we decided to remove these two countries as well. This left approximately 166,000 individuals across 34 countries for inclusion in this study. ${ }^{9}$ Despite these reductions, Western and Eastern European countries are both well-represented in our sample. The Western European set consists of around 98,000 individuals across 19 countries, and the Eastern European set has around 67,000 individuals across 15 countries. Population weights are applied for the macro-analysis.

In light of our theoretical discussion, we have also included data showing the size of the immigrant population and the size of the Muslim population of the countries involved in order to determine possible connections between the size of the minorities and the attitudes in the country in the most recent survey of 2017. The size of the immigrant population was calculated by the authors by comparing it to the relative size of the population using data from the UN international migrant stock, which offers estimates of the foreignborn population in the receiving countries..$^{10}$ The percentage of the Muslim population is based on estimates from a report by the Pew Research Center. The estimates show the percentage of the Muslim population in various countries in 2016. Countries estimated to have fewer than 10,000 Muslims were assigned a percentage of $0.1 \%$. Russia, Belarus, Serbia and Iceland were not included in the report; therefore, the estimates for Russia, Belarus and Serbia are based on a separate Pew Research Center report on religious affiliation in Central and Eastern Europe. ${ }^{11}$ An important point to consider is that Muslims can be understood as different groups in different European countries. For example, in several Eastern Europe, such as Russia, Serbia and Bulgaria, Muslims may be viewed both as immigrants and an indigenous ethnic minority, while in most Western European countries Muslims are almost exclusively associated with an immigrant background.

\section{Data and methods pseudo-panel data}

An additional aim of this study was to test whether the construction of pseudo-panel data can be used for studying attitudes across time on a micro level. As the data collected by EVS were not collected from the same individuals at the four different time points selected, ordinary panel data cannot be used to analyse the data. Deaton (1985) suggested the creation of pseudo-panel data to counter this issue. Pseudo-panels are created by grouping similar individuals into cohorts. The key concept is that individuals who share

\footnotetext{
${ }^{9}$ The countries included in the analysis were: Austria (AT), Belgium (BE), Bulgaria (BG), Belarus (BY), Croatia (HR), the Czech Republic (CZ), Denmark (DK), Estonia (EE), Finland (FI), France (FR), Germany (DE), Greece (GR), Hungary (HU), Iceland (IS), Ireland (IE), Italy (IT), Latvia (LV), Lithuania (LT), Luxembourg (LU), Malta (MT), Netherlands (NL), Norway (NO), Poland (PL), Portugal (PT), Romania (RO), Russia (RU), Serbia (RS), Slovakia (SK), Slovenia (SI), Spain (ES), Sweden (SE), Switzerland (CH), Ukraine (UA), United Kingdom (UK). Data retrieved from https://europeanvaluess tudy.eu/, where more information on procedure and methodological documentation is provided.

10 Data can be downloaded from: https://www.un.org/en/development/desa/population/migration/data/estimates2/ estimates17.asp

11 Data can be downloaded from: https://www.pewforum.org/2017/11/29/europes-growing-muslim-population/n Data from Russia, Belarus and Serbia can be downloaded from: https://www.pewforum.org/2017/05/10/religious-affil iation/. We could not find a reliable estimate of the Muslim population of Iceland and have therefore excluded the country from this part of the analysis.
} 
the same sociodemographic criteria face similar social experiences and therefore may harbour similar attitudes. Based on this technique, we used the EVS data to construct panel data at the level of sociodemographic groups. Each of these groups was coded with the mean value on each variable measured for the group. Therefore, instead of analysing individuals over time, we are analysing cohorts over time (Liu \& Tan, 2009). ${ }^{12}$

In the literature on prejudice, gender, age and education can be seen to influence attitudes towards ethnic minorities (see Ceobanu \& Escandell, 2010 for review). In stratifying our sociodemographic groups, we used these three sociodemographic variables. The respondents' gender comprises two groups (male or female). Age was classified into eight groups using the respondents birth year: (1) Pre 1929, (2) 1930-1939, (3) 19401949, (4) 1950-1959, (5) 1960-1969, (6) 1970-1979 (7) 1980-1989 and (8) individuals born post 1990. Educational level was classified into three groups: (1) lower educational level, (2) middle educational level and (3) higher educational level. ${ }^{13}$ The variable measuring education was first introduced to the questionnaire in the 1999 survey. Consequently, the pseudo-panel analysis uses the data from 1999, 2008 and 2017.

After the groups were created, each sociodemographic group was coded with the mean value of each variable. With a total of 34 countries and 48 sociodemographic groups $(2 \times 8 \times 3)$, we could have theoretically ended up with a total of 1632 groups $(34 \times 48)$; however, the actual number of real groups was 1622 , with a mean of 87 individuals in each group. The group sizes vary from one individual in eleven groups to 560 individuals in three groups. The size of each group was then weighted against the number of people in each group which tells us that we end up with a total of 3913 individuals in 1622 groups across three time periods.

With the data having been transformed into a pseudo-panel, we were then able treat it as ordinary panel data, with the benefits such a method entails. The only difference is that instead of looking at how a specific individual changes over time, we are seeing how an average individual in a sociodemographic group changes over time. For example, this means that we can investigate how increased trust in the press over time may have affected the anti-Muslim attitudes of an average highly educated Italian male born between 1970 and 1979 in the period of 1999-2017.

\section{Independent variables}

An issue when working with cross-sectional data collected at three different time periods is that identical variables need to be included in all three datasets. EVS has several good variables that can be used to analyse for the use of analysing what may affect people's attitudes. However, many of these variables are either not included in all three of our datasets, or the wording of the question is different in one of the datasets, making the variable unsuitable for our purposes. We are, therefore, limited to a smaller set of adequate independent variables for the analysis than would be optimal.

\footnotetext{
${ }^{12}$ It should be noted that pseudo-panel analysis is a different approach to age-period-cohort models. We measure how average individuals change their attitudes across time, while the latter approach measures how generational shifts affect attitudes across time.

13 Lower educational level includes individuals with no education or those who attained primary and lower secondary education. Middle educational level includes individuals with upper secondary and post-secondary education. Higher educational level includes bachelor's level and master's or higher.
} 
In total, there are 9 independent variables that measure different aspects that may affect the attitudes towards either immigrants or Muslims. From the variable Proud of nationality $(1=$ Not very proud, $4=$ Very proud), we may explore whether more pride in one's nationality equates to individuals being more intolerant, as a greater extent of national pride may enhance the feeling of being in a dominant in-group and may cause people to view both Muslims and immigrants as exterior threats to their nationality. Two occupational categories are also included, as unemployed $(0=$ not unemployed, $1=$ unemployed $)$ individuals may view immigrants as competitors for jobs (Blumer, 1958), and students $(0=$ Not student, $1=$ Student $)$ as education can be seen as a socialisation arena for more liberal values (Hello et al., 2002). Left/right measures the respondents' placement on the political spectrum on a 10 -point scale where $1=$ Left and $10=$ Right. We include this variable to see whether more right-leaning individuals are connected to more prejudice, as several previous studies have indicated. Furthermore, we also explore whether there may be differences in the effect of this variable between Western and Eastern Europe.

We also included two variables representing different facets of social trust: Trust in press $(1=$ None at all, $4=\mathrm{A}$ great deal $)$ and Trust in others $(0=$ Can't be too careful, $1=$ Most people can be trusted). As the media may play a role in shaping the perceptions of both immigrants and Muslims, and because Muslims are often portrayed stereotypically in the media, it may be relevant to explore whether more trust in the press indicates a higher level of intolerance. Social trust has also been found by some studies to influence attitudes towards ethnic outgroups (Herreros \& Criado, 2009). Therefore, it is relevant to analyse whether Trust in others may have an effect on how immigrants and Muslims are perceived. Furthermore, we have included a variable measuring how satisfied the respondent is with their life as a whole $(0=$ Dissatisfied, $10=$ Satisfied $)$, as individuals who are dissatisfied with their life are hypothesised to be more likely to blame outgroups for their negative personal condition (McLaren, 2003).

The variable Political system: Democratic (having a democratic system $-1=$ very bad, $4=$ very good) is included, based on an assumption that individuals who are less satisfied with a democratic system will be more hostile towards immigrants and Muslims, as they will be more prone to identifying with authoritative political leaders' anti-immigrant rhetoric. ${ }^{14}$

Finally, as Muslims are a religious minority, we have also added a measurement of the respondents' level of religiosity. To measure this, we have chosen to include a variable measuring how important God is to the respondent $(0=$ Not at all important, $10=$ Very important). It is pertinent to explore whether Muslims are viewed by religious individuals as a religious threat. Results regarding the effect of religiosity on prejudice are rather mixed, with previous studies finding that religiosity can have a positive, negative and no effect on attitudes towards ethnic outgroups (Laythe et al., 2002; Bell, \& Strabac, 2020).

${ }^{14}$ For more on the rationale behind this assumption see Ágh (2014). 


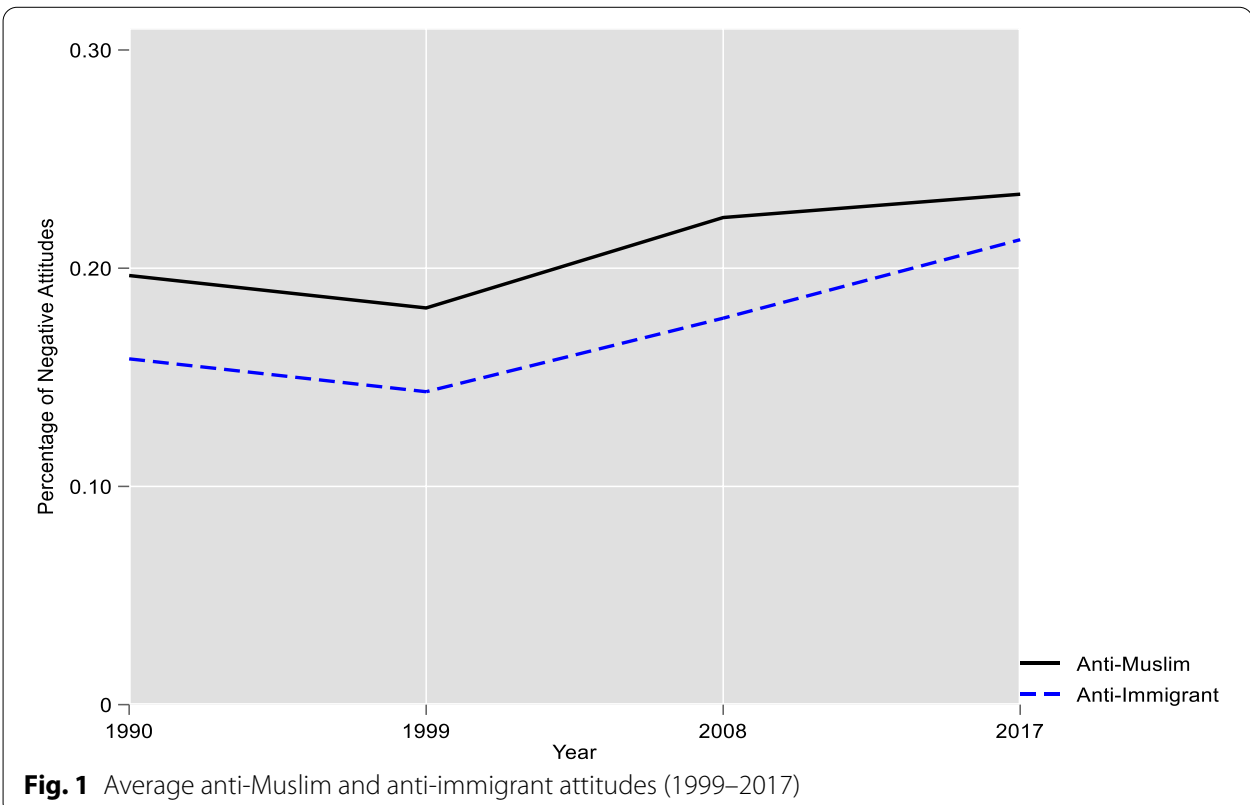

\section{Results}

In what follows, we explore changes over time in the attitudes towards Muslims and immigrants, both at the macro and micro levels. We first present results from the changes in attitudes across time, before proceeding with an analysis on the current levels of intolerance in 2017. Figure 1 shows the average anti-Muslim and anti-immigrant attitudes in Europe in the period from 1990 to 2017.

As can be seen in Fig. 1, there does appear to have been a rise in intolerance towards the two outgroups across Europe from 1999 to 2017. We can see that in the whole period covered by our data, anti-Muslim attitudes remained higher than anti-immigrant attitudes. Anti-Muslim attitudes increased at the highest rate in the period 1999 to 2008. In this period, we observe an increase in the share of respondents stating that they would not like to have Muslims as neighbours (from 18.3 to 22.2\%). Yet, in the period from 2008 to 2017, there was somewhat of a smaller increase of respondents stating that they would not like to have Muslims as neighbours.

Anti-immigrant attitudes have also been rising across Europe. From 1999 to 2008, there was a rise from 14.4 to $17.6 \%$ of respondents stating that they would not like to have immigrants as neighbours, increasing further to $21.3 \%$ in 2017 , and slowly gaining on the levels of anti-Muslim attitudes. In sum, Fig. 1 shows us that in 2017, more than one-fifth of Europeans harboured negative attitudes towards Muslims and immigrants.

Previous studies have found that there is a significant difference in attitudes towards minorities between Western and Eastern Europe (Bello, 2017; Gorodzeisky \& Semyonov, 2019). To further investigate this, we split the data into an Eastern Europe set and a Western Europe set, showing the average anti-Muslim and anti-immigrant attitudes in the two halves of Europe. Figure 2 shows developments in Eastern and Western Europe in the period from 1990 to 2017.

Figure 2 shows several interesting findings. The first is that contrary to the general trends presented in Fig. 1, anti-Muslim and anti-immigrant attitudes have actually decreased in Western Europe in the period from 2008 to 2017. This is an interesting 


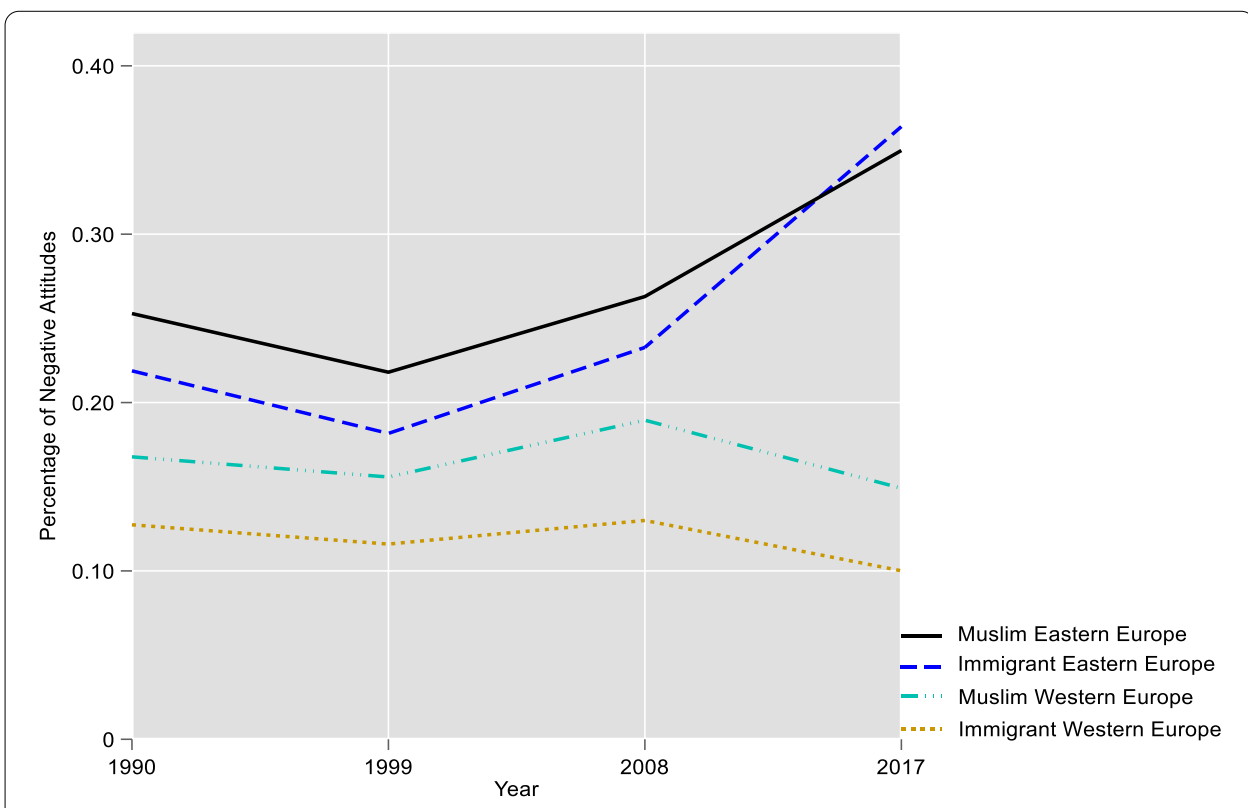

Fig. 2 Average anti-Muslim and anti-immigrant attitudes in Western Europe and Eastern Europe (1990-2017)

finding, especially if we take into consideration that support for right-wing populist parties went up in the period from 2008 to 2017 in several Western European countries; the negative attitudes actually decreased in this period to levels similar to those in $1999 .{ }^{15}$ However, the figure shows the opposite trend in Eastern Europe. Indeed, negative attitudes have increased considerably in Eastern Europe, with anti-Muslim and anti-immigrant attitudes going from an average of $21.8 \%$ and $18.6 \%$ respondents stating that they would not like to have immigrants and Muslims as neighbours in 1999 to a staggering 35\% and 36.4\% in 2017, showing that over one-third of Eastern Europeans harboured negative attitudes towards Muslims and immigrants. This high level of negative attitudes in Eastern Europe actually disguises the trend of decreased negative attitudes in Western Europe in the combined European graphs in Fig. 1. The later pseudo panel analysis also suggests that there is a strong time trend in anti-immigrant and anti-Muslim attitudes that is constant across Eastern European countries.

We have further analysed the time-trends by breaking down the data into two different age-groups; Individuals born before and after 1975 to see if there are any differencing regarding individuals coming of age pre/post cold war and communist rule (See Appendix: Figs. 5, 6). Here, we found a similar trend to Fig. 2 in Eastern Europe. The trend in Western Europe shows that the post-1975 generation have higher levels of anti-Muslim attitudes than the pre-1975 generation. ${ }^{16}$ This is in line with researchers who assert that Muslims are increasingly perceived as not harbouring liberal and universalist values, which in turn

\footnotetext{
${ }^{15}$ Dennison and Geddes (2018) also found similar results regarding decreased anti-immigrant attitudes. They point to immigrant saliency being the major factor for the rise of right-wing populist parties in Western Europe, not anti-immigrant attitudes.

16 This is especially interesting as younger generations tend to be less intolerant than older generations (Ceobanu \& Escandell 2010)
} 
may lead to more intolerance in the more liberal and secular younger generation in Northwestern Europe (Helbling \& Traunmüller, 2018, Simonsen \& Bonikowski 2020).

As the most intriguing aspect of Fig. 2 takes place between 2008 and 2017, we also replicated the figure using data from the European Social Survey which covers the same period, but with more time points with similar variables (see Appendix: Fig. 7). The figure shows the same trend as Fig. 2, with decreased intolerance in Western Europe and increased intolerance in Eastern Europe. ESS data also indicates that the decreasing trend in Western Europe began from 2010. In Eastern Europe, the trend began to increase seriously in the period between 2012 and 2014. In other words, the trend was already well on the way before the refugee crisis of 2015-2016, which we will discuss in more detail later in the article.

Another surprising finding is the relationship between anti-Muslim and anti-immigrant attitudes in both Western and Eastern Europe. In Western Europe, the relationship has been rather stable across time, following what previous studies have found in that negative attitudes towards Muslims tend to be more pronounced than negative attitudes towards immigrants more generally (Strabac \& Listhaug, 2008; Gorodzeisky \& Semyonov, 2019). This seems to be the case in Eastern Europe from 1990 to 2008; however, in 2017, both anti-immigrant and anti-Muslim attitudes are around the same level.

In addition to the macro analysis of changes in attitudes, we have explored the potential of the pseudo-panel approach for analysing individual attitudes over time. Table 1 shows our results using the pseudo-panel data, with model 1 exploring anti-immigrant attitudes in Western and Eastern Europe and model 2 exploring anti-Muslim attitudes in Western and Eastern Europe.

We start the pseudo-panel analysis with the findings from Western Europe before moving on to the Eastern European model and end the analysis with a comment on the effect of the year dummies. Our findings show that in Western Europe, if a group on average becomes more satisfied with their life, the less intolerant towards both immigrants and Muslims the group will become. The more pro-democracy a group on average becomes is also associated with a more positive attitude towards both immigrants and Muslims. As it was expected, models 1 and 2 also show that, in Western Europe, the more right-leaning on the political spectrum a group becomes, the more intolerant towards both immigrants and Muslims they will be. The findings in Western Europe are interesting as they show that the same independent variables have similar effects for both anti-immigrant attitudes and anti-Muslim attitudes. These results confirm findings from previous studies on attitudes towards immigrants and Muslims (Strabac \& Listhaug, 2008; Savelkoul et al., 2011).

There is only one variable that has an effect in explaining the attitudes in Eastern Europe. The more religious a group on average becomes in Eastern Europe, the more intolerant they will become towards immigrants. Interestingly, it does not have the expected effect on anti-Muslim attitudes, as it was expected that Muslims may be viewed as a religious threat. None of the independent variables has a significant effect on antiMuslim attitudes in Eastern Europe. That only one variable has an effect on the attitudes in Eastern Europe may mean that there is need for updated theoretical models for this region, something previous studies have also suggested (Vala \& Pereira, 2018).

While the micro-analysis yields few significant effects for understanding the anti-Muslim and anti-immigrant attitudes in Eastern Europe, the year dummies show interesting effects, which should be commented on. Year dummies are included in fixed effects 
Table 1 Pseudo-panel analysis of anti-immigrant and anti-Muslim attitudes in Western and Eastern Europe

\begin{tabular}{|c|c|c|c|c|}
\hline & \multicolumn{2}{|c|}{ Model 1: Anti-immigrant } & \multicolumn{2}{|c|}{ Model 2: Anti-Muslim } \\
\hline & Western Europe & Eastern Europe & Western Europe & Eastern Europe \\
\hline & Fixed effects & Fixed effects & Fixed effects & Fixed effects \\
\hline \multirow[t]{2}{*}{ Satisfied with life } & $-0.023^{* *}$ & -0.004 & $-0.030^{* *}$ & -0.021 \\
\hline & $(0.008)$ & $(0.014)$ & $(0.009)$ & $(0.015)$ \\
\hline \multirow[t]{2}{*}{ Trust in Press } & -0.035 & -0.008 & 0.003 & -0.054 \\
\hline & $(0.021)$ & $(0.067)$ & $(0.021)$ & $(0.065)$ \\
\hline \multirow[t]{2}{*}{ Trust in others } & -0.008 & 0.014 & -0.061 & 0.124 \\
\hline & $(0.027)$ & $(0.072)$ & $(0.037)$ & $(0.071)$ \\
\hline \multirow[t]{2}{*}{ Left/right spectrum } & $0.015^{*}$ & -0.009 & $0.015^{* *}$ & 0.006 \\
\hline & $(0.005)$ & $(0.014)$ & $(0.005)$ & $(0.016)$ \\
\hline \multirow[t]{2}{*}{ Politcal system: Democratic } & $-0.058^{*}$ & 0.022 & $-0.066^{*}$ & -0.023 \\
\hline & $(0.027)$ & $(0.045)$ & $(0.026)$ & $(0.042)$ \\
\hline \multirow[t]{2}{*}{ Proud of nationality } & -0.027 & 0.078 & -0.033 & 0.081 \\
\hline & $(0.018)$ & $(0.045)$ & $(0.016)$ & $(0.042)$ \\
\hline \multirow[t]{2}{*}{ How important: God } & 0.001 & $0.024^{*}$ & 0.005 & 0.002 \\
\hline & $(0.007)$ & $(0.010)$ & $(0.006)$ & $(0.011)$ \\
\hline \multirow[t]{2}{*}{ Unemployed } & 0.054 & -0.073 & 0.020 & -0.087 \\
\hline & $(0.041)$ & $(0.077)$ & $(0.046)$ & $(0.101)$ \\
\hline \multirow[t]{2}{*}{ Student } & 0.022 & -0.028 & 0.029 & -0.055 \\
\hline & $(0.018)$ & $(0.043)$ & $(0.018)$ & $(0.040)$ \\
\hline \multicolumn{5}{|c|}{ Year dummy (1999 as reference) } \\
\hline \multirow[t]{2}{*}{2008} & 0.021 & 0.033 & $0.053^{* *}$ & 0.036 \\
\hline & $(0.014)$ & $(0.028)$ & $(0.017)$ & $(0.029)$ \\
\hline \multirow[t]{2}{*}{2017} & $0.038^{*}$ & $0.157^{* *}$ & $0.058^{* *}$ & $0.145^{*}$ \\
\hline & $(0.016)$ & $(0.049)$ & $(0.018)$ & $(0.066)$ \\
\hline N & 2095 & 1727 & 2094 & 1727 \\
\hline Within $R^{2}$ & 0.110 & 0.397 & 0.163 & 0.307 \\
\hline
\end{tabular}

Standard errors in parentheses

${ }^{*} p<0.05 ;{ }^{* *} p<0.01 ; * * * 0<0.001$

models to capture effects that are constant across countries but vary over time (Stock \& Watson, 2012). In Table 1, we can see that the 2017 dummy has an effect in all four models, however there is a much stronger effect in both of the Eastern European models. It may therefore be that there is a strong Eastern European time trend in anti-immigrant and anti-Muslim attitudes that is constant across countries, which we are not able to capture in our models.

\section{Cross-country variations in anti-Muslim and anti-immigrant attitudes}

As the results from the time-analysis found diverging attitudes in Western and Eastern Europe, it would be of interest to look at the attitudes that can be found in each individual country. In Fig. 3a, b, we see the country-specific averages for anti-Muslim and anti-immigrant attitudes in $2017 .{ }^{17}$ 


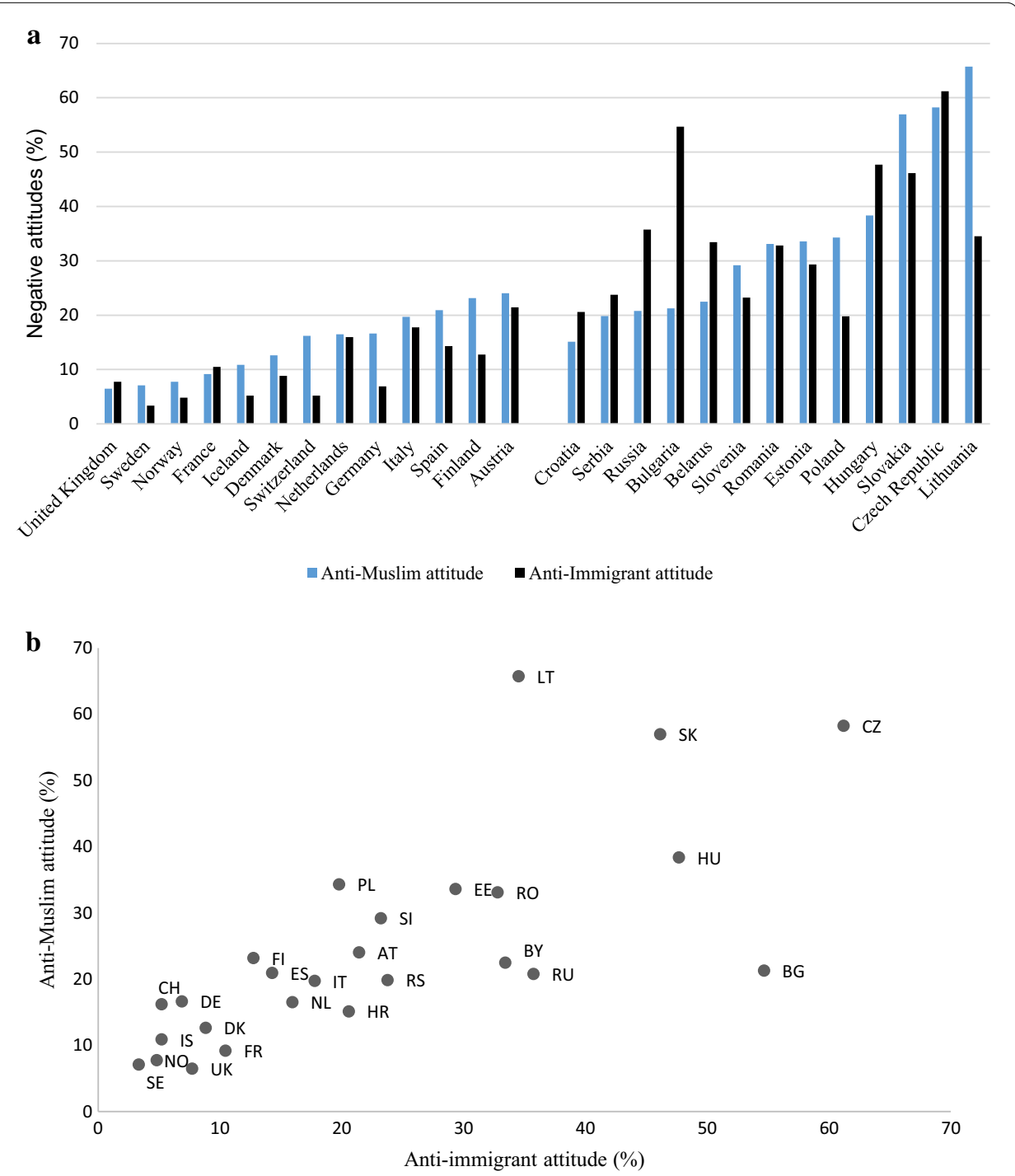

Fig. 3 a Country-specific anti-Muslim and anti-immigrant attitudes in Europe (2017). b Country-specific scatterplot of anti-Muslim and anti-immigrant attitudes in Europe

Figure 3a shows that there is a large discrepancy in attitudes amongst the countries, both in Western and Eastern Europe. Amongst the most tolerant countries in Western Europe are Sweden, Norway and the United Kingdom, where fewer than 10\% of respondents state that they would not like to have immigrants and Muslims as neighbours. ${ }^{18}$ These countries are much more tolerant than Austria, Italy, Finland and Spain, where between 15 and $20 \%$ of respondents would not like to have immigrants and Muslims as neighbours.

\footnotetext{
${ }^{18}$ As more institutionalized democracies have a stronger anti-racist norm (Ramos et al., 2020), it is important to keep in mind the social desirability bias when examining the results in several Western European countries.
} 
In Eastern Europe, there are also very large differences between the countries, with Bulgaria, the Czech Republic, ${ }^{19}$ Hungary and Slovakia having extremely high levels of intolerance. By contrast, Croatia is nowhere near these levels of intolerance. Comparatively, Croatia is amongst the most tolerant countries when compared to its Eastern European counterparts. Yet, when compared to the Western European countries, it fits amongst the most intolerant Western countries, alongside Austria, Italy, Finland and Spain. It is a rather fitting example of the differences in intolerance between Western and Eastern Europe that the most tolerant Eastern European country would be one of the more intolerant countries if compared to the Western European countries.

Figure 2 gives the impression that there were similar levels of anti-Muslim and antiimmigrant attitudes in Eastern Europe in 2017. However, when examining Fig. 3b, we can see that this may be more the case in Western Europe, as there is a clustering in the bottom left corner of several Western European countries. There are, however, discrepancies between the prominence of anti-Muslim and anti-immigrant attitudes in several Eastern European countries, with the most prominent examples being the cases of Lithuania and Bulgaria. The case of Lithuania shows us that $34.53 \%$ of the respondents exhibit an anti-immigrant attitude, while a staggering $65.72 \%$ exhibit anti-Muslim attitudes. By contrast, Bulgaria shows a different pattern, with the average level of antiMuslim attitudes being $21.27 \%$ and the average level of anti-immigrant attitudes in the country being $54.67 \%$. A possible explanation for these variations may be the differences in the size of the immigrant and Muslim populations in the countries. As already noted, Muslims in Bulgaria are primarily an ethnic minority and not primarily associated with migrants which seems to influence attitudes. Other Eastern European countries that also have non-immigrant Muslim minorities such as Russia, Serbia and Croatia, exhibit lower levels of anti-Muslim attitudes than other Eastern European countries. Previous studies also suggest that a larger size of a Muslim minority may reduce prejudice towards Muslims (Schlueter et al., 2020). This is in line with Fig. 4a, which shows that Bulgaria has a large Muslim population, and has relatively similar levels of anti-Muslim attitudes to many Western European countries.

Figure 4a also shows that the countries where Muslim populations are virtually nonexistent are the countries where there are the highest levels of anti-Muslim attitudes. Figure $4 \mathrm{~b}$ also shows similar trends, in that a larger immigrant population is generally related to a lower level of anti-immigrant attitude. In many ways, these figures confirm what Renata Włoch (2009) termed "phantom islamophobia". Indeed, countries such as Lithuania, the Czech Republic and Slovakia have extreme levels of anti-Muslim attitudes, despite there being near non-existent Muslim populations in all three countries. The figure also shows support for Schlueter and colleagues' finding that a larger Muslim population is associated with decreased levels of anti-Muslim attitudes (Schlueter et al., 2020).

During the communist period, immigration to several Eastern European countries was marginal. This has led to several Eastern European countries having small immigrant populations and some countries having virtually no Muslim minorities. Several scholars

19 The case of the Czech Republic is somewhat astonishing when examining the change in attitudes across time; antiMuslim and anti-immigrant attitudes were around 15 and 19 percent in 1999, rising to around 30 percent for both in 2008 and finally reaching around 60 percent in 2017. See Appendix: Table 2 for the country-specific intolerance from 1990 to 2017. 


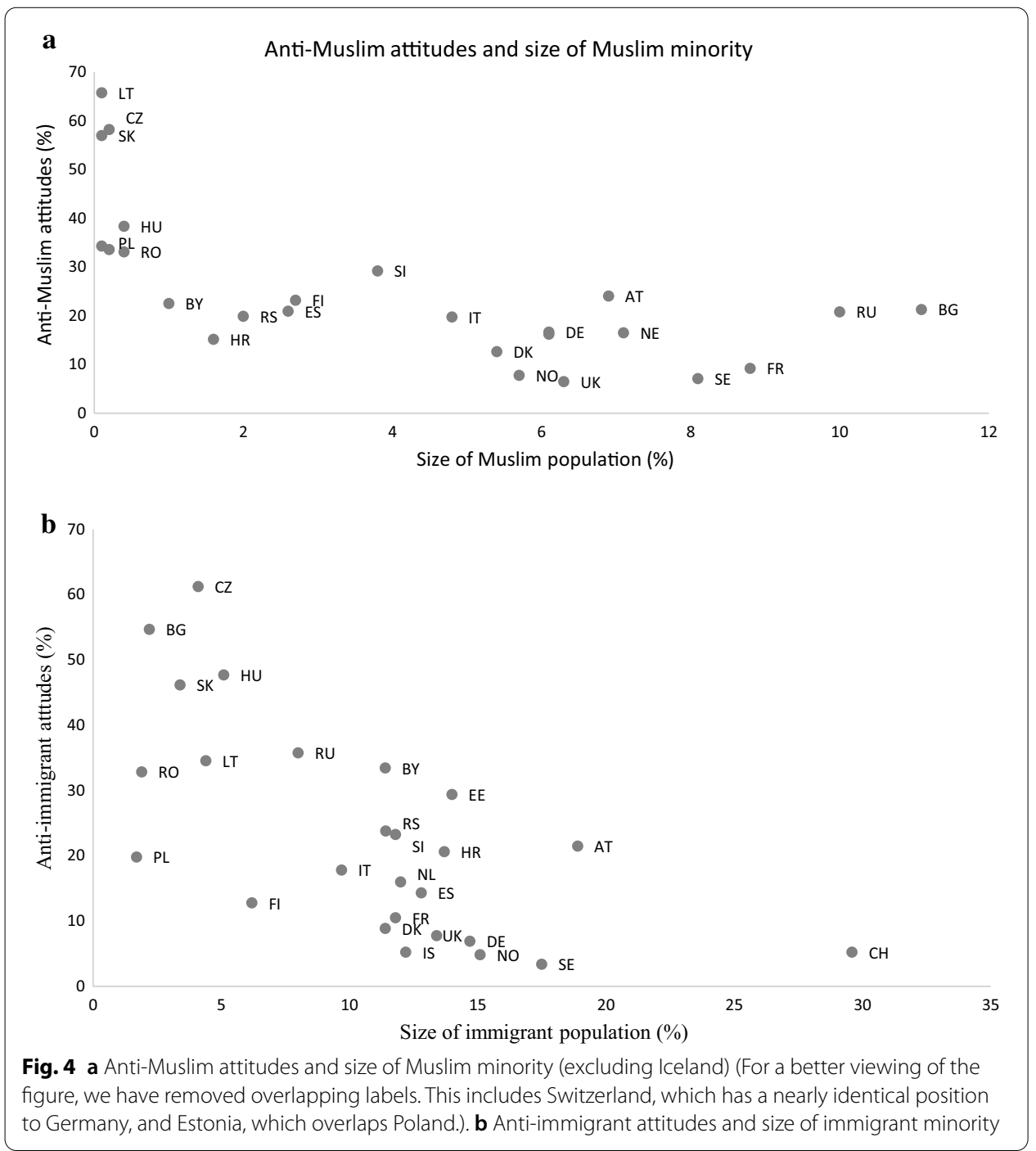

believe that a possible explanation for the higher levels of intolerance in Eastern European countries is the lack of intergroup contact between the majority population and ethnic outgroups (Pickel \& Öztürk, 2018). Both Fig. 4a, b provide indirect support to this argument, showing that the Eastern European countries with fewer immigrants or Muslims have higher levels of intolerance. According to this argument, a lack of contact with the two ethnic groups means there is little opportunity to reduce negative attitudes (Włoch, 2009; Pickel \& Öztürk, 2018).

Another important external factor, which has sometimes been related to changes in attitudes over time, is the refugee crisis of 2015-2016 (Stockemer et al., 2020). It should be noted that the EVS data from 2017 were collected right after the large influx of refugees in 2015 and 2016, when Europe received more than one million refugees from Syria and other countries (Valenta \& Jakobsen, 2020). We have already shown that intolerance has increased in Europe in the last decades. However, it was also noted that the high levels of negative attitudes in Eastern Europe disguise the trend of decreased negative attitudes in Western Europe. 
Indeed, it seems that the influx of refugees did not result in increased intolerance in most Western European countries, not even in Germany and Sweden, the countries that received in the largest share of the refugees in 2015 and 2016 (Valenta \& Jakobsen, 2020). As already noted, in 2017, these countries exhibited some of the lowest levels of intolerance towards immigrants and Muslims in the whole sample. Furthermore, in the period 2008-2017, anti-immigrant and anti-Muslim attitudes declined in Western Europe, including in the above-mentioned countries that were the two major receiving nations of refugees. ${ }^{20}$

In contrast, Eastern European countries such as the Czech Republic, Slovakia and Lithuania exhibited the highest levels of intolerance in 2017 in the whole of Europe. Anti-immigrant and anti-Muslim attitudes increased significantly in these countries in the period 2008-2017, but this can hardly be explained by the refugee influx, as these countries received negligibly low numbers of refugees in 2015 and 2016. However, we cannot exclude indirect effects of the refugee influx on attitudes in Eastern European countries, such as the increased media focus on the refugee crisis, "imported islamophobia”, populations' anxiety regarding a possible influx of refugees and other aforementioned factors and misconceptions (Włoch, 2009; Pickel \& Öztürk, 2018; Stockemer et al., 2020).

\section{Concluding discussion}

Studies of prejudice have continued to find higher levels of intolerance in Eastern Europe than in Western Europe, despite most immigrants and Muslims residing in Western Europe. We therefore outlined two main aims for this study. The two main aims were to explore the differences in anti-immigrant and anti-Muslim attitudes in Western and Eastern Europe and to explore these differences over time. We found that the great increases in both anti-Muslim and anti-immigrant attitudes in Eastern Europe disguises the trend of decreased intolerance in Western Europe. Additionally, the relationship between anti-Muslim and anti-immigrant attitudes has remained rather stable in Western Europe between 1990 and 2017, with Muslims being continually more exposed to negative attitudes than immigrants.

Furthermore, our findings show that, on average, anti-immigrant and anti-Muslim attitudes have reached similar levels in Eastern Europe. However, when looking at the country-specific data, there are large discrepancies between the anti-Muslim and antiimmigrant attitudes in several Eastern European countries. A possible explanation for this may be the relationship between the size of the minority and the intolerant attitudes, as has been proposed by previous studies. ${ }^{21}$ Indeed, our findings show that the larger the proportion of immigrant or Muslim populations, the lesser the degree of intolerant attitudes. ${ }^{22}$ Previous studies have also shown that it is the perceived size of the minority and not the factual size that may increase the levels of threat perceptions, which in

\footnotetext{
${ }^{20}$ Countries in Southern Europe were also strongly affected by the refugee crisis in 2015, and anti-Muslim and antimigrant sentiments have recently increased in Italy, Spain and Croatia, but they are still considerably lower compared to those in Eastern Europe. Recall table 2 in Appendix.

21 See Schlueter \& Wagner (2008); see also Pettigrew \& Tropp (2006), Verkuyten et al (2010).

${ }^{22}$ Lack of contact to counter stereotypical representations of Muslims or immigrants may therefore explain the differences between Western and Eastern Europe. This may explain why a country like Lithuania has extreme levels of antiMuslim attitudes, despite the Muslim population making up around 0.1 percent of the population.
} 
turn increases negative attitudes (Gorodzeisky \& Semyonov, 2020). Indeed, it is evident that Muslims and immigrants are perceived to make up a greater size of the population than in actuality in Eastern Europe (see, amongst others, Ipsos, 2016; Gorodzeisky \& Semyonov, 2020). ${ }^{23}$ This misperception of the size and threat of the minorities and no intergroup contact opportunities could therefore be a possible explanation for the higher levels of intolerance in Eastern Europe. We were, however, unfortunately not able to test this in this analysis.

The most pressing question after this analysis is related to the sudden divergence in trends from 2008. We found that the decreasing trend in Western Europe began in 2010, while it began to increase steeply in Eastern Europe between 2012 and 2014, continuing to climb from 2014 to 2016. ${ }^{24}$ Two crises hit most of Europe between 2008 and 2017, the first being the 2008 financial crisis, the second being the refugee crisis of 2015-2016. It is evident that countries hit hard by the financial crisis also tended to have an increase in hostility towards immigrants (Isaksen, 2019). The decreasing trend from 2010 may be the aftermath after high levels of intolerance collected from samples during the crisis. Interestingly, the initial rise of intolerance in Eastern Europe began before the refugee crisis of 2015, and does not seem to have changed initially from the 2008 financial crisis.

The numbers of irregular migrants increased in some of the Eastern European countries before 2015. For example, Bulgaria and Hungary experienced a significant increase in influx a few years before numbers of asylum seekers peaked in Western Europe in 20152016. This may explain some of the indicated increase in intolerance, but not the increase in intolerance in Poland, Czech Republic, Lithuania and other Eastern European countries that hardly experienced the refugee crisis. The continuing increase from 2014 in these countries is therefore more likely the result of the refugee crisis seeing the proximity of several of the countries to the main migration route and the increased in politicization and saliency of immigration in Eastern European countries (Hutter \& Kriesi, 2021). ${ }^{25}$

We have indicated that average levels of intolerance are lower in Western Europe than in Eastern Europe. Furthermore, the average levels of intolerance towards immigrants and Muslims are decreasing in Western Europe, including in the countries that received the largest numbers of migrants during the refugee crises of 2015 and 2016. It should, however, be noted that although Western European countries have lower levels of intolerance towards immigrants and Muslims, this does not necessarily mean that "all is well" in Western Europe. There are high levels of intolerance in several Western European countries, including Austria, Finland, Spain and Italy. Although these levels are lower than in the most intolerant cases in Eastern Europe, they are not negligible.

This article has also explored the potential and limitations of EVS in micro-level explorations of changes in attitudes over time. EVS does not provide panel data. We have therefore constructed a pseudo-panel with the data to see if it could be used to analyse changes over time in average individuals' attitudes towards Muslims and

\footnotetext{
${ }^{23}$ With some Eastern European countries having virtually no Muslim minority population, there is no opportunity for intergroup contact to counter the images people receive from media outlets (Saeed 2007; Wloch 2009).

24 See the Appendix: Fig. 7 using ESS data.

25 Hutter and Kriesi (2021) found that in some Eastern European countries, immigration went from not being politicized at all, to be very politicized following the increased influx of irregular migrants.
} 
immigrants. We found that although some variables have an effect, the main finding from the pseudo-panel analysis is the effect of the year dummies, as they show that there is a strong Eastern European trend towards intolerant attitudes that is stable across the countries and which our models were not able to capture.

To summarise: For our purposes, the EVS provides a good foundation for macro analysis of changes over time in attitudes of people in Europe. However, it does not provide a sufficient frame for the analysis of changes in individual attitudes, and the shortages embedded in the EVS can be only partly amended via a pseudo-panel analysis. Nevertheless, we believe that future studies should focus more on the worrying trend of negative attitudes that can be found, especially in Eastern Europe. Comparative case studies of individual countries, using both historical and cultural factors to explain the attitudes in the countries, may enhance our knowledge of the reasons behind the development of very high levels of intolerance in several of these countries. Studies exploring the relationship between lack of contact and intolerance in Eastern Europe would also be a welcome addition to the research field of prejudice.

\section{Appendix}

See Figs. 5, 6, 7 and Table 2.

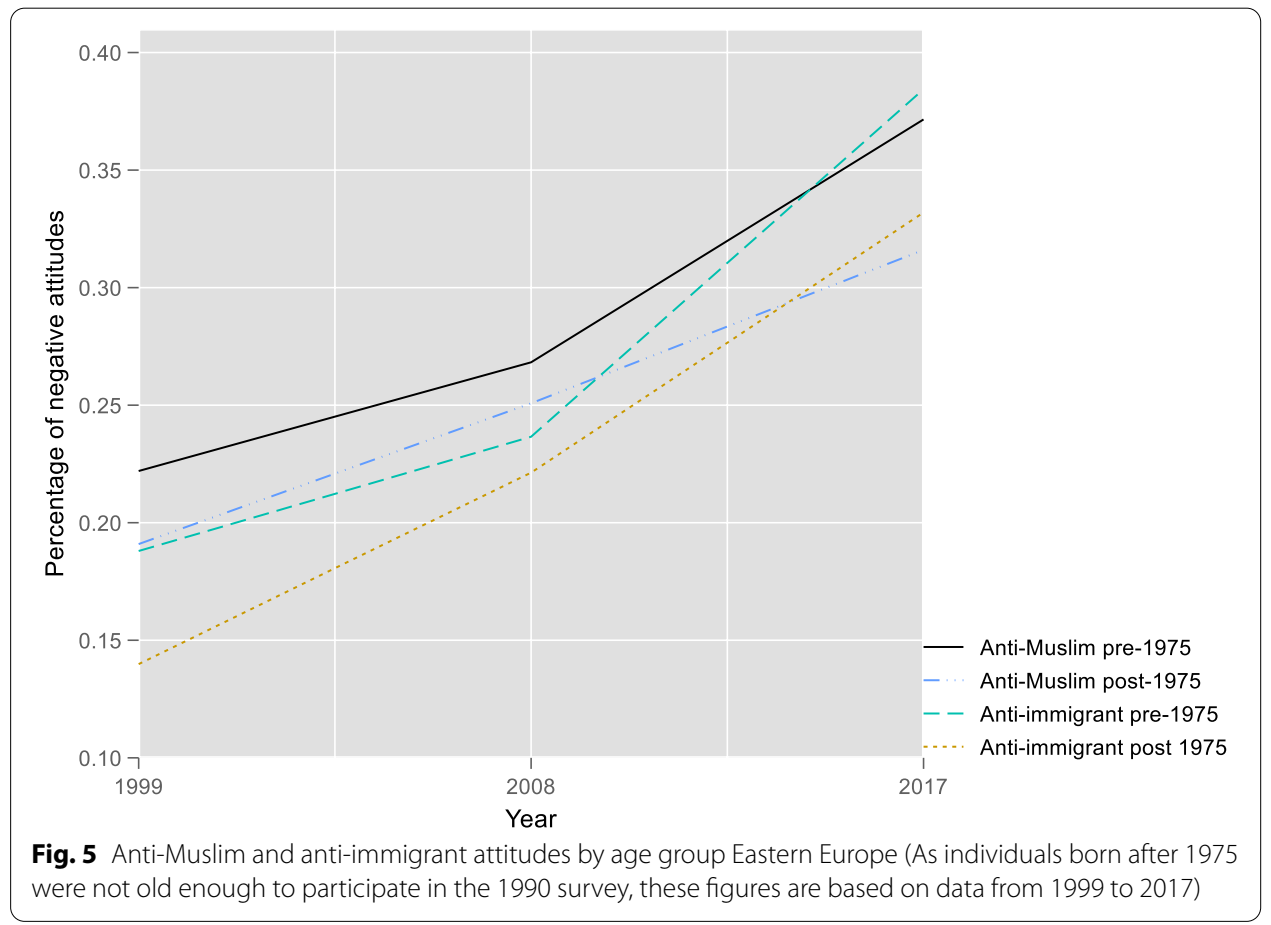




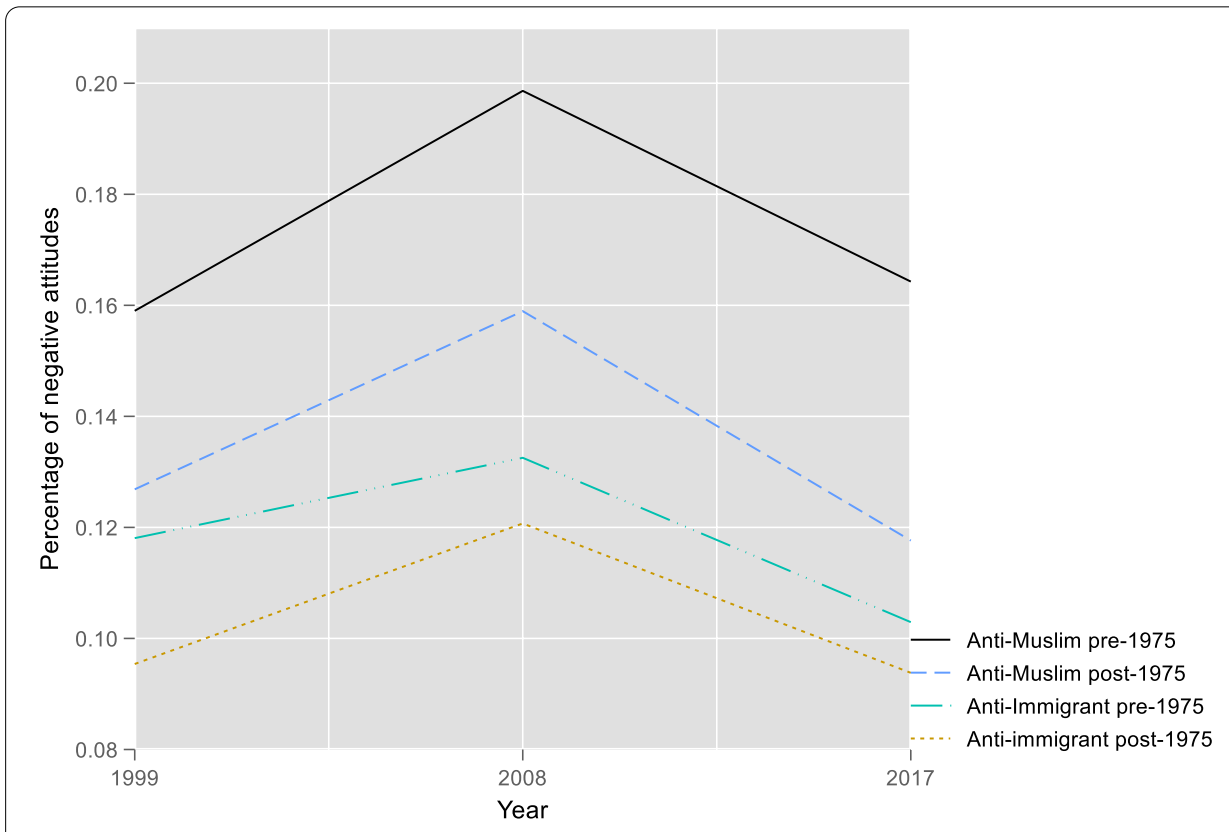

Fig. 6 Anti-Muslim and anti-immigrant attitudes by age group Western Europe

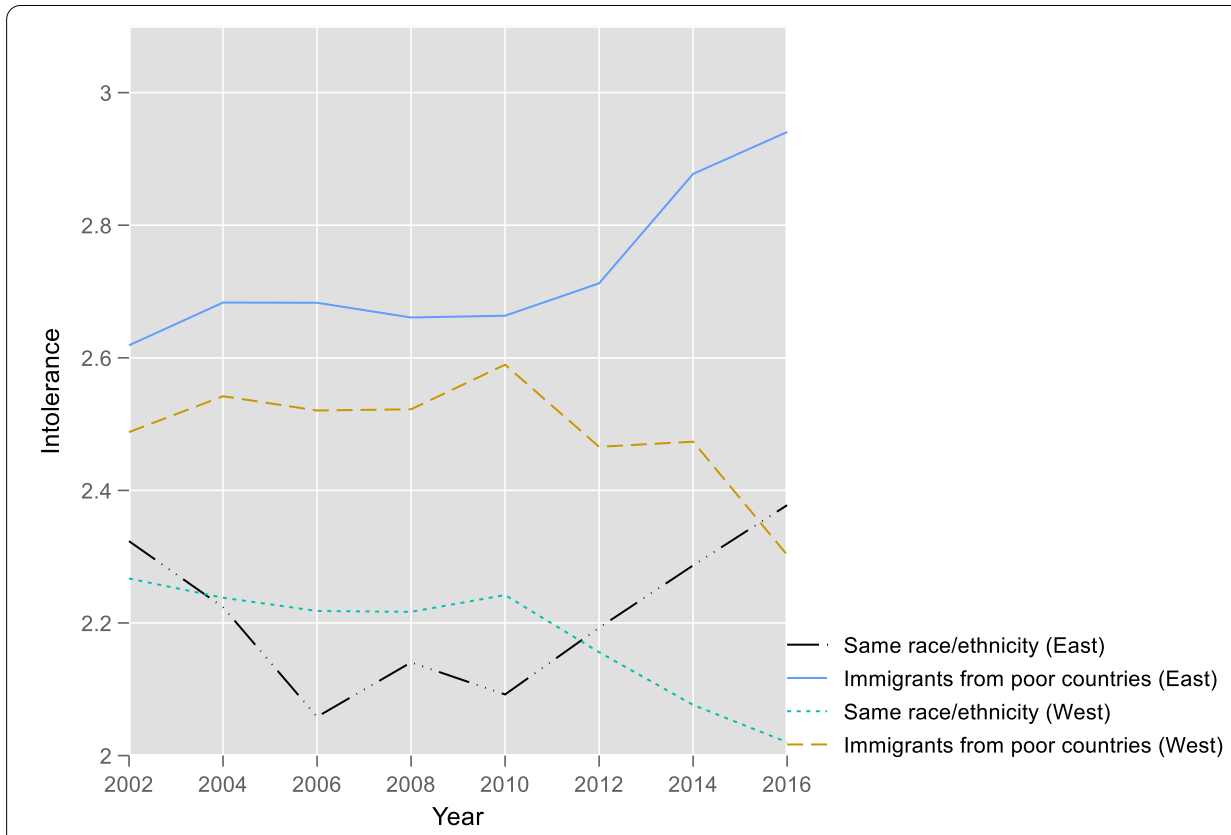

Fig. 7 Time trends for attitudes towards immigrants of the same race towards immigrants from poor countries outside of Europe. Data from European Social Survey 


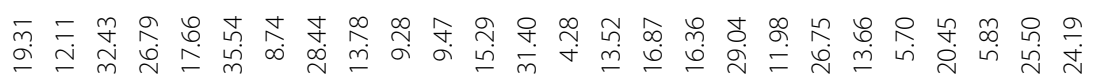

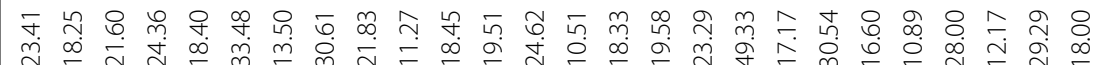
$\sim$

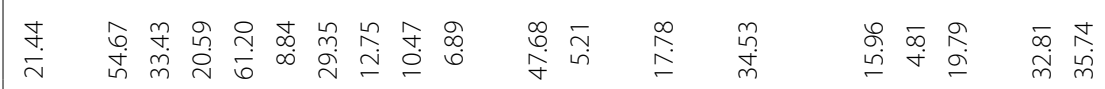

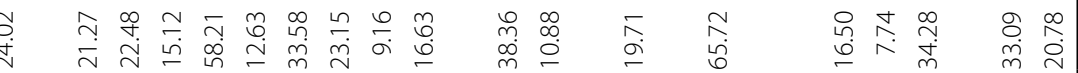

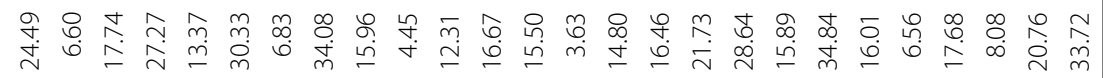

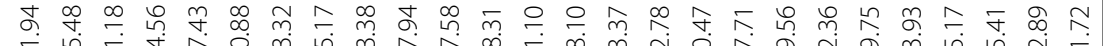
m

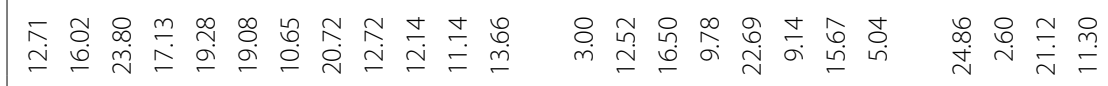

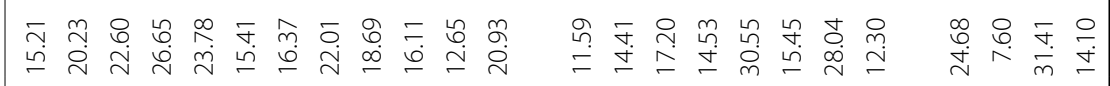




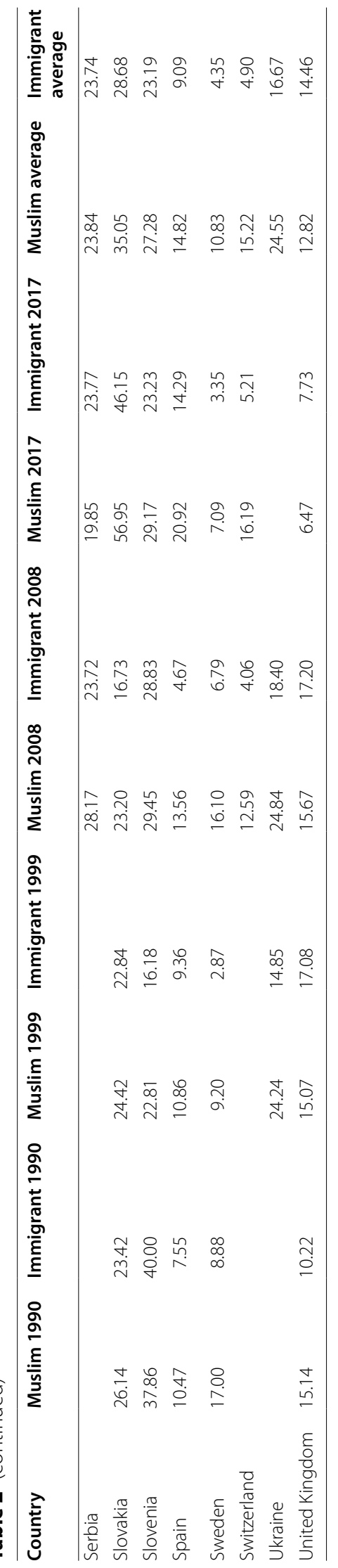




\section{Acknowledgements}

Not applicable.

\section{Authors' contributions}

$D A B$ is the main author of this paper. MV has contributed throughout the process, with an emphasis on the results and concluding discussion. ZS has contributed throughout the process, with an emphasis on the methods and results. All authors read and approved the final manuscript.

\section{Funding}

Not applicable.

\section{Availability of data and materials}

The data used for this study is: The European Value Study (1990-2017), available at: https://europeanvaluesstudy.eu/. UN Migration stock, available at: https://www.un.org/en/development/desa/population/migration/data/estimates2/estim ates17.asp. PEW Research Center, available at: https://www.pewforum.org/2017/11/29/europes-growing-muslim-popul ation/n. The European Social Survey, available at: https://www.europeansocialsurvey.org/.

\section{Declarations}

\section{Competing interests}

Not applicable.

\section{Author details}

'Department of Social Work, Norwegian University of Science and Technology, 7491 Trondheim, Trondelag, Norway. ${ }^{2}$ Department of Sociology and Political Science, Norwegian University of Science and Technology, 7491 Trondheim, Trondelag, Norway.

Received: 1 February 2021 Accepted: 25 September 2021

Published online: 23 November 2021

\section{References}

Ágh, A. (2014). Decline of democracy in East-Central Europe: The last decade as the lost decade in the ECE democratization. Journal of Comparative Politics, 7, 4-33

Allport, G. W. (1954). The nature of prejudice. Addison-Wesley.

Andersen, H., \& Mayerl, J. (2018). Attitudes towards Muslims and fear of terrorism. Ethnic and Racial Studies, 41, 2634-2655. Bell, D. A., \& Strabac, Z. (2020). Exclusion of Muslims in Eastern Europe and Western Europe. A comparative analysis of anti-muslim attitudes in France, Norway, Poland and Czech Republic. International Journal on Minority and Group Rights, 28(1), 117-142.

Bello, V. (2017). International migration and international security: Why prejudice is a global security threat. Routledge. Ben-Nun Bloom, P., Arikan, G., \& Lahav, G. (2015). The effect of perceived cultural and material threats on ethnic preferences in immigration attitudes. Ethnic and Racial Studies, 38, 1760-1778.

Blalock, H. M. (1967). Toward a theory of minority-group relations. Wiley.

Blumer, H. (1958). Race prejudice as a sense of group position. Pacific Sociological Review, 1, 3-7.

Brubaker, R. (2017). Between nationalism and civilizationism: The European populist moment in comparative perspective. Ethnic and Racial Studies, 40, 1191-1226.

Ceobanu, A. M., \& Escandell, X. (2010). Comparative analyses of public attitudes toward immigrants and immigration using multinational survey data: A review of theories and research. Annual Review of Sociology, 36, 309-328.

Citrin, J., \& Sides, J. (2008). Immigration and the imagined community in Europe and the United States. Political Studies, $56,33-56$.

Czaika, M., \& Di Lillo, A. (2018). The geography of anti-immigrant attitudes across Europe, 2002-2014. Journal of Ethnic and Migration Studies, 44, 2453-2479.

Czymara, C. S. (2020). Propogated preferences? Political elite discourses and Europeans' openness toward Muslim immigrants. International Migration Review, 54, 1212-1237.

Das, E., Bushman, B., Bezemer, M. D., Kerkhof, P., Vermulen, I., \& E. . (2009). How terrorism news reports increase prejudice against outgroups: A terror management account. Journal of Experimental Social Psychology, 45, 453-459.

De Cock, R., Mertens, S., Sundin, E., Lams, L., Mistiaen, V., Joris, L., \& Dhaenens, L. (2018). Refugees in the news: Comparing Belgian and Swedish newspaper coverage of the European refugee situation during the summer 2015. Communications, 43, 301-323.

Deaton, A. (1985). Panel data from time series of cross-sections. Journal of Econometrics, 30, 109-126.

Dennison, J., \& Geddes, A. (2019). A rising tide? The salience of immigration and the rise of anti-immigration political parties in Western Europe. The Political Quarterly, 90, 107-116.

Elchardus, M., \& Spruyt, B. (2014). Universalism and anti-Muslim sentiment. International Journal of Intercultural Relations, 38, 75-85.

Esposito, J. L., \& Kalin, I. (2011). Islamophobia: The challenge of pluralism in the 21st century. Oxford University Press.

Gorodzeisky, A. (2019). Opposition to immigration in contemporary Russia. Post-Soviet Affairs, 35, 205-222.

Gorodzeisky, A., \& Semyonov, M. (2019). Unwelcome immigrants: Sources of opposition to different immigrant groups among Europeans. Frontiers in Sociology, 4, 24

Gorodzeisky, A., \& Semyonov, M. (2020). Perceptions and misperceptions: Actual size, perceived size and opposition to immigration in European societies. Journal of Ethnic and Migration Studies, 46, 612-630.

Hello, E., Scheepers, P., \& Gijsberts, M. (2002). Education and ethnic prejudice in Europe: Explanations for cross-national variances in the educational effect on ethnic prejudice. Scandinavian Journal of Educational Research, 46, 5-24. 
Hellbling, M. (2014). Opposing Muslims and the Muslim headscarf in Western Europe. European Sociological Review, 30, 242-257. Helbling, M., \& Traunmüller, R. (2018). What is islamophobia? Disentangling citizens'feelings towards ethnicity, religion and religiosity using a survey experiment. British Journal of Political Research, 50, 811-828.

Herreros, F., \& Criado, H. (2009). Social trust, social capital and perceptions of immigration. Political Studies, 57, 337-355.

Hutter, S., \& Kriesi, H. (2021). Politicizing immigration in times of crises. Journal of Ethnic and Migration Studies. https://doi. org/10.1080/1369183X.2020.1853902

IPSOS 2016. Perceptions are not reality: What the world gets wrong. Retrieved from https://www.ipsos.com/ipsos-mori/ en-uk/perceptions-are-not-reality-what-world-gets-wrong. (Viewed 13th February 2020).

Isaksen, J. V. (2019). The impact of the financial crisis on European attitudes toward immigration. Comparative Migration Studies, $7,1-20$

Jæger, M. M. (2013). The effect of macroeconomic and social conditions on the demand for redistribution: A pseudo panel approach. Journal of European Social Policy, 23, 149-163.

Laythe, B., Finkel, D. G., Bringle, R. G., \& Kirkpatrick, L. A. (2002). Religious fundamentalism as a predictor of prejudice: A two-component model. Journal for the Scientific Study of Religion, 41, 623-635.

Legewie, J. (2013). Terrorist events and attitudes toward immigrants: A natural experiment. American Journal of Sociology. $118,1199-1245$.

Liu, H., \& Tan, W. (2009). The effect of anti-smoking media campaign on smoking behavior: The California experience. Annals of Economics \& Finance, 10, 29-47.

Mclaren, L. M. (2003). Anti-immigrant prejudice in Europe: Contact, threat perception, and preferences for the exclusion of migrants. Social Forces, 81, 909-936.

Meuleman, B., Davidov, E., \& Billiet, J. (2009). Changing attitudes toward immigration in Europe, 2002-2007: A dynamic group conflict theory approach. Social Science Research, 38, 352-365.

Pettigrew, T. F., \& Tropp, L. R. (2006). A meta-analytic test of intergroup contact theory. Journal of Personality and Social Psychology, 90, 751 .

Pichler, F. (2010). Foundations of anti-immigrant sentiment: The variable nature of perceived group threat across changing European societies, 2002-2006. International Journal of Comparative Sociology, 51, 445-469.

Pickel, G., \& Öztürk, C. (2018). Islamophobia Without Muslims? The "contact hypothesis" as an explanation for anti-Muslim attitudesEastern European societies in a comparative perspective. Journal of Nationalism, Memory \& Language Politics, 12, 162-191.

Pottie-sherman, Y., \& Wilkes, R. (2017). Does size really matter? On the relationship between immigrant group size and anti-immigrant prejudice. International Migration Review, 51, 218-250.

Ramos, A., Pereira, C. R., \& Vala, J. (2020). The impact of biological and cultural racisms on attitudes towards immigrants and immigration public policies. Journal of Ethnic and Migration Studies, 46(3), 574-592.

Ribberink, E., Achterberg, P., \& Houtman, D. (2017). Secular tolerance? Anti-Muslim sentiment in Western Europe. Journal for the Scientific Study of Religion, 56, 259-276.

Saeed, A. (2007). Media, racism and Islamophobia: The representation of Islam and Muslims in the media. Sociology Compass, 1, 443-462.

Savelkoul, M., Scheepers, P., Tolsma, J., \& Hagendoorn, L. (2011). Anti-Muslim attitudes in The Netherlands: Tests of contradictory hypothjesis derived from ethnic competition theory and intergroup contact theory. European Sociological Review, 27, 741-758.

Simonsen, K. B., \& Bonikowski, B. (2020). Is civic nationalism necessarily inclusive? Concepts of nationhood and antiMuslim attitudes in Europe. European Journal of Political Research, 59, 114-136.

Schlueter, E., Masso, A., \& Davidov, E. (2020). What factors explain anti-Muslim prejudice? An assessment of the effects of Muslim population size, institutional characteristics and immigration-related media claims. Journal of Ethnic and Migration Studies, 46, 649-664.

Schlueter, E., \&Wagner, U. (2008). Regional differences matter: Examining the dual influence of the regional size of the immigrant population on derogation of immigrants in Europe. International Journal of Comparative Sociology, 49, 153-173.

Semyonov, M., Raijman, R., \& Gorodzeisky, A. (2006). The rise of anti-foreigner sentiment in European societies, 19882000. American Sociological Review, 71, 426-449.

Strabac, Z., Aalberg, T., Jenssen, A. T., \& Valenta, M. (2016). Wearing the veil: Hijab, Islam and job qualifications as determinants of social attitudes towards immigrant women in Norway. Ethnic and Racial Studies, 39(15), 2665-2682.

Strabac, Z., \& Listhaug, O. (2008). Anti-Muslim prejudice in Europe: A multilevel analysis of survey data from 30 countries. Social Science Research, 37(1), 268-286.

Stephan, W. G., Ybarra, O., \& Rios, K. (2015). Intergroup Threat Theory. In T. D. Nelson (Ed.), Handbook of prejudice, stereotyping and discrimination. Psychology Press.

Stock, J. H. \& Watson, M. M. (2012). Introduction to econometrics. Pearson Education Limited.

Stockemer, D., Niemann, A., Unger, D., \& Speyer, J. (2020). The "Refugee Crisis", immigration attitudes, and Euroscepticism. International Migration Review, 54, 883-912.

Vala, J., \& Pereira, C. R. (2018). Racisms and normative pressures: A new outbreak of biological racism? In M. C. Lobo, F. C. da Silva, \& J. P. Zucuete (Eds.), Changing societies: Legacies and challenges. Citizenship in crisis. (Vol. 2). ICS.

Valenta, M., \& Jakobsen, J. (2020). Conceptualising Syrian war migrations: Displacements, migrants' rights and the major reception regimes. International Journal on Minority and Group Rights, 28(1), 143-166.

Verkuyten, M., Thijs, J., \& Bekhuis, H. (2010). Intergroup contact and ingroup reappraisal: Examining the deprovincialization thesis. Social Psychology Quarterly, 73, 398-416.

Wike, R., \& Grim, B. J. (2010). Western views toward Muslims: Evidence from a 2006 cross-national survey. International Journal of Public Opinion Research, 22, 4-25.

Włoch, R. (2009). Islam in Poland: Between ethnicity and universal umma. International Journal of Sociology, 39, 58-67.

\section{Publisher's Note}

Springer Nature remains neutral with regard to jurisdictional claims in published maps and institutional affiliations. 